\title{
Trauma of the Pelvic Ring: Epidemiological and Etiopathogenic Aspects
}

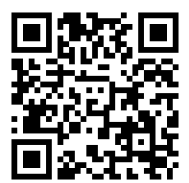

\author{
Diouf AB*, Gueye AB, Dembele B, Daffe M, Dia R, Sarr L, Diop PS, Coulibaly NF, Sane AD and Dieme CB \\ Orthopedics Traumatology, Aristide Le Dantec Hospital, West Africa
}

Received: April 19, 2018; Published: April 30, 2018

*Corresponding author: Alioune Badara Diouf, Orthopedics Traumatology Aristide Le Dantec Hospital, Avenue Pasteur BP 3001, West Africa

\section{Introduction}

The injuries of the pelvic ring are the set of mechanical lesions affecting the pelvic girdle formed by the 2 iliac bones, the sacrum and the coccyx. The acetabular cavity is an anatomical region belonging to the pelvis, but its articular function makes the lesions acetabulum is considered an entity separate from other pelvic lesions [1]. It is an infrequent emergency, related to generally violent trauma. They represent 0.3 to $9.3 \%$ of all trauma [2-4]. They are the preserve of the young active adult.

\section{Objectives}

The aim of our work is to analyze the traumatisms of the pelvic ring, to study their epidemiological and etiopathogenic profiles in the department of Orthopedic Surgery and Traumatology of Aristide Le Dantec University Hospital.

\section{Materials and Methods}

Our work is a descriptive retrospective study of pelvic ring injuries collected at the Department of Orthopedic Surgery and Traumatology at the Aristide Le Dantec University Hospital Center. It took place over a period of ten [5] years from January 1, 2005 to December 31, 2015. This study concerned patients received and followed for pelvic ring trauma. They numbered 119 and according to the criteria of non-inclusion, 103 were retained. Our data was collected from emergency consultation records and hospital discharge records. It was thus established for each patient a record of exploitation on which we collected the epidemiological data, Etiopathogenic. We used the software SPHINX for the collection and analysis of the data in order to transcribe them on EXCEL for the graphs and tables of the different variables of our study. With the IBM SPSS 20.00 software, we crossed certain data of our study for determine Pearson's Chi-square p. The results were significant if the $\mathrm{p}$ was less than 0.05 .

\section{Results}

The average age was 34.3 years, with extremes of 10 years and 75 years. (Figures $1 \& 2$ 2) 47 summarizes the different age classes recorded. We had 69 men and 34 women, a sex ratio of 2.03 . The professions were diverse and varied. There were 12 of them. Students and students were mostly found (Table 1).The circumstances of occurrence were, in order of frequency, traffic accidents (79\%), work-related accidents (17\%), defenestration (3\%) and domestic accidents (1\%). In 51 cases (49.52\%) the lesional mechanism was lateral compression; anteroposterior compression accounted for 31 cases (30.1\%); we also obtained 13 cases of combined mechanism $(12.62 \%)$ and 8 cases of shear $(7.76 \%)$.

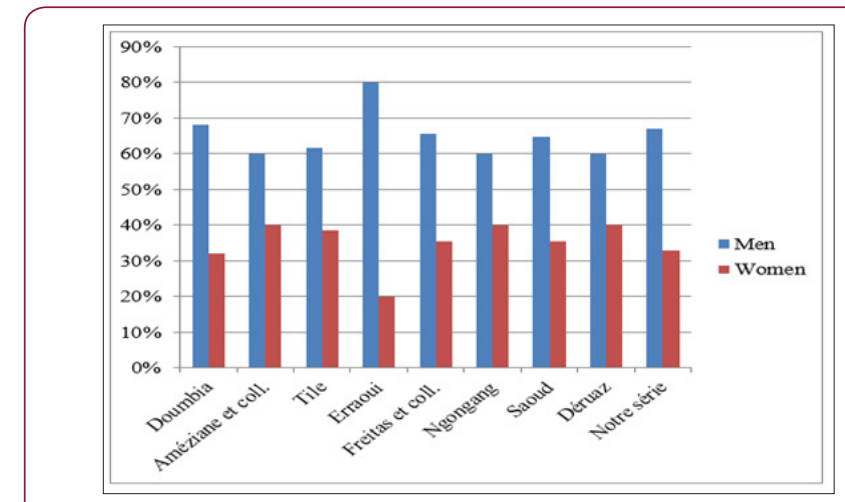

Figure 1: Male-female ratio in the different studies.

Table 1: Professions.

\begin{tabular}{|c|c|c|}
\hline Professions & Effectives & Percentage \\
\hline Shoe shiner & 1 & $0,971 \%$ \\
\hline Joiner & 1 & $0,971 \%$ \\
\hline Teacher & 3 & $2,91 \%$ \\
\hline Tailor & 3 & $2,91 \%$ \\
\hline Merchant & 6 & $5,83 \%$ \\
\hline Driver and apprentice & 6 & $5,83 \%$ \\
\hline surface technician & 7 & $6,80 \%$ \\
\hline Mechanic & 8 & $7,80 \%$ \\
\hline Older & 11 & $10,70 \%$ \\
\hline
\end{tabular}




\begin{tabular}{|c|c|c|}
\hline Unemployed & 13 & $12,62 \%$ \\
\hline Bricklayer & 13 & $12,62 \%$ \\
\hline Student-student & 31 & $30,10 \%$ \\
\hline TOTAL & 103 & 100 \\
\hline
\end{tabular}

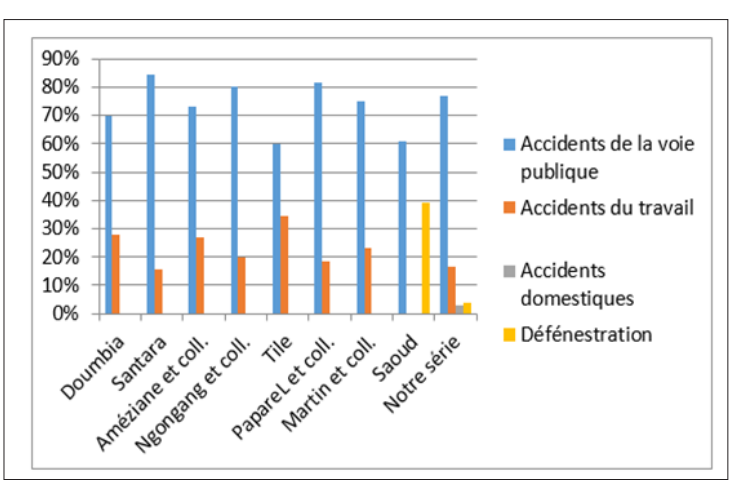

Figure 2: Circumstances of occurrence according to studies.

\section{Discussion}

At the epidemiological level, the most affected age group is between 20 and 29 years old with $25.24 \%$. This result is consistent with that of Traoré [6] and Santara [7], which regain a peak between 21 and 30 years with respectively $30.55 \%$ and $37.5 \%$. Indeed, in the literature, the age group most exposed to trauma of the pelvic ring is between 15 and 30 years old [8]. This confirms the theory that trauma to the pelvic ring is the preserve of the young adult. It is aware of this stage of life that the human being is more active and dynamic on the socio-professional level. There is a relationship between age and the circumstances of occurrence ( $p$ $=0.02$ ). Individuals under 40 , constituting more than $75 \%$ of the population in our regions [9], are the most affected in our study. In children, certain constitutional features are taken into account: the flexibility and great deformability of the pelvis expose it less to this type of traumatic lesion. On the other hand, at an advanced age with the association of osteoporosis-related defects, the exposure is more manifest because of the existing bone fragility.

Table 2: Age variation by series.

\begin{tabular}{|c|c|c|}
\hline Studies & Average Age (years) & Extreme (years) \\
\hline Améziane et coll. & 40 & $(15-66)$ \\
\hline Doumbia & 29,5 & $(6-58]$ \\
\hline Hanane Farah & 36 & $(14-76]$ \\
\hline Santara & 28,2 & $(10-67]$ \\
\hline Traoré et coll. & 36,27 & $(18-55]$ \\
\hline Tile & 34,2 & $(15-81]$ \\
\hline Our series & 34,3 & {$[10-75]$} \\
\hline
\end{tabular}

However, since these people are less active, these fractures are rarely found at this age (Table 2).Male dominance is the rule in most studies $[3,8,10,11]$. In our series, $67 \%$ of patients are men with a sex ratio of 2.03. This major finding is confirmed by a correlation found between sex and the circumstances of occurrence $(p=0.01)$. Indeed in our countries, the man is mostly more affected whatever the circumstances of occurrence. He is deemed to be more active and therefore more exposed to traffic road [9]. This particularly masculine youth is known to be hyperactive and dynamic in the job market and more concerned with road traffic [9]. In addition, in occupational accidents, we find a high proportion of men. The most plausible explanation would be the absence of women in high-risk occupations such as masonry (work sites, scaffolding). Added to this is the non-compliance with safety standards such as the wearing of clogs, helmets and the use of archaic materials in construction sites namely the constitution of scaffolding by rudimentary materials.

Compared with the results of our series, most authors agree that the male age-distribution curve of fractures is of the bimodal type with a first peak in the young adult and a second peak in the segment of the population over the age of $50[4,10,12,13]$. These results are similar to those of Doumbia[1], Oumar Saud [14] and Freitas [11] which respectively find $68 \% ; 64.7 \%$ and $62.5 \%$ of males.Concerning the circumstances of occurrence, traffic accident dominate the table with $76.7 \%$. The latter are the first providers of trauma in the pelvis [8] and are clearly in the lead in 50 to $83 \%$ of cases according to the studies [3,4,10]. Améziane [10], Santara [7], Ngongang [4], Paparel [15] found concordant results with respectively $73 \% ; 84.38 \% ; 80 \%$ and $81.5 \%$. The increase in the number of cars, two-wheeled vehicles and the narrowness of our roads, which do not often meet the required standards in terms of width and safety markings [9], seem to be the major causes of the occurrence of trauma of the pelvic ring. The state of the vehicles often without an up-to-date technical visit and the non-respect of the code of the road in our countries are not insignificant factors.

Moreover, we note a lack of materialization of the tracks that are borrowed concomitantly by pedestrians [9]. In our study, $58.23 \%$ of traffic accident are for pedestrians.During the traffic accident by collision between two vehicles we noticed that the drivers are less concerned with $2.53 \%$ of the traffic accident while the front and rear passengers are the victims with $29.11 \%$. We believe that the survival or defense reflex could drive drivers to protect themselves to the detriment of other passengers. It would be interesting to continue this reflection in the other future works.The distribution of socio-professional layers is quite varied. However some professions may be more at risk especially in the building industry with high place falls. Compliance with established safety standards should be put in place by employers. Domestic accidents are found in our study whereas they do not exist in most authors $[4,7,10,15]$. It will be necessary to look in our contexts if the standards of construction are respected [16-20]. Indeed some families live in unfinished houses and sometimes in very precarious conditions compared to lighting; which exposes [21-26].

\section{Conclusion}

Thus at the end of our study, we make the following recommendations:

a. Improving the condition of the road network and vehicles to reduce the high prevalence of traffic accidents [26-30],

b. The establishment and dissemination of a traffic accident prevention policy, the technical control of vehicles, the 
construction of footbridges for pedestrians, the decluttering of sidewalks, rigor in the issuance of driving licenses [31-34],

c. Awareness of road users to respect safety standards,

d. The requirement for a driving license for two-wheeled vehicles,

e. Mandatory wearing of the seatbelt [35-39],

f. Compliance with safety standards in the workplace,

g. Psychological support.

\section{References}

1. DoumbiaSouleymane (2011) Studies of pelvic fractures in the Orthopedic Surgery and Trauma Department of Gabriel Touré Teaching Hospital.Medical Thesis, Bamako No. 103.

2. Barzilay Y, Liebergall M, Ori Safran MD, Amal Khoury, Rami Mosheiff (2005) Pelvic fractures in a trauma center: a test case for the efficacy of the trauma system in Israel. Imaj-Ramat Gan 7(10): 619.

3. Deruaz AC (2001) Fracture of pelvis and acetabulum: long-term result. Thesis of Doctorate of State in Medicine, University of GenevaN ${ }^{\circ} 107$.

4. Ngongang GFO, Paul F, Achille M, Agnes E, Gael L, et al. (2014) Fractures of the pelvic ring: epidemiological, clinical and radiological aspects.J Afr Imag Med 4(6): 35-41.

5. Eida M(1983)Fracture of the pelvis.Postgrad med J 50: 650-55.

6. Traore O, Compaore TM, Sawadogo M, Bandre E, Yilboudo J (1997) Traumatic fractures of the pelvis; epidemiological aspects and management.Medicine of Black Africa 44(12): 630-634.

7. Mohamed Santara (2007) Fractures of the pelvis: epidemiological, clinical and therapeutic study.Medical Thesis, Bamako $\mathrm{N}^{\circ} 88$.

8. Gansslen A, Krettek C (2006) Epidemiology of unstable fractures of the pelvic ring and associated lesions. In The fractures and disjunctions of the pelvic ring of the adult. (Eds.). NordinJY, TonettiJSOFCOT monograph $\mathrm{N} \circ$ 92, Elsevier, Paris, France, 37-44.

9. Faye MWhat strategies to improve road safety in Africa?35th Annual General Meeting of the Federation of African National Insurance Companies.

10. Ameziane L, Mahfoud M, Madhi T, El Bardouni A, El Yaacoubi M (1999) Injuries in the pelvis in adults outside of acetabulum (about 56 cases). Maghreb Medicine 73: 17-22.

11. Freitas CD, Garotti JE, Nieto J, Guimaraes RP, Ono NK (2013) There have been changes in the incidence and epidemiology of pelvic fractures in recent decades. Rev BrasilOrtop 48(6): 475-481.

12. Hanane Farah (2014) The pelvic trauma: epidemiological, therapeutic and prognostic aspects (60 cases).Thesis of Medicine, Marrakech $\mathrm{N}^{\circ}$ 149.

13. Tile M (1996) Acute pelvic fractures: Causation and classification. J Am Acad Orthop Surg 4(3): 143-51.

14. Oumar Saoud (2011) Management of pelvic fractures.Thesis of Medicine, Rabat $\mathrm{N}^{\circ} 144$.'

15. Paparel P, Bardet L, Tayot O, Fessy MH, Souli M, Souli AL (2007) Fractures of the pelvis. Medical and Surgical Encyclopedia, Elsevier-Masson, Paris, France 25: 100-110.

16. Barsotti J, Cancel J, Robert CPractical guide of traumatology. ( $6^{\text {th }}$ edn.), Elsevier-Masson, Paris, France, pp. 189-95.
17. Cryer HM, Miller FB, Henry M, Mark B, Frank B (1988) Pelvic fracture classification: Correlation with haemorrhage. J Trauma 28(7): 973-980.

18. Demetriades D, Karaiskakis D, Toutouzas K, Alo K, Chan L et al. (2002) Pelvic fractures: epidemiology and predictors of associated abdominal injuries and outcomes. J Am Coll Surg 195(1): 1-10.

19. Dje K, Yao B, Sanou B, Kokoua A, Gnananzan KG (2007) Urogenital complications of trauma pelvis about 41 cases.Black Afr Med 54: 53-59.

20. Donaldson L, Cook A, Thomson RG(1990) Incidence of fractures in a geographically defined population. Journal of Epidemiology and Community Health 44(3): 241-245.

21. Gansslen A, Pohlemann T, Paul C, Lobenhoffer P, Tscherne H (1996) Epidemiology of pelvic ring injuries.Injury, Paris: Elsevier 27: 13-20.

22. Hochbe E, Stone N (1993) Bladder fracture associated with pelvic fracture due to blunt trauma. Urology 41(6): 531-533.

23. Kellam JF, Browner BD (1992) Fractures of the pelvic ring. In: Skeletal trauma BD Browner, Jupiter JB, Levine AM, PG Trafton (eds). Saunders, Philadelphia, US, 44(17): 849-897.

24. Mariam Erraoui (2010) Unstable fractures of the pelvis.Thesis of Medicine, Marrakech $\mathrm{N}^{\circ} 164$.

25. Mccormack R, Strauss EJ, Basil J, Tejwani C (2010) Diagnosis of Pelvic Fractures. Bulletin of the NYU Hospital for Joint Diseases 68(4): 281291.

26. Melton LJ, sampson JP (1981) Epidemiologic fractures of pelvis fractures. Chir Orthop Relate Res USA 155: 43-47.

27. Mcleod M, Powell J (1997) Evaluation of pelvic fractures: Clinical and radiologic. Orthop Clin North Am 28(3): 299-319.

28. Mouhsine E, Garofalo R, Theumann N, Borens O, Chevalley F,et al. (2008) Trauma of the pelvis. Swiss Medical Review 4: 20723-30.

29. Mroueh J (1985) Pelvic fractures and their complications. Anatomoclinical and therapeutic aspects of 109 observations.Surgery thesis Dakar.

30. Peltier LF (1965) Complications associated with fractures of the pelvis. J Bone, joined joint Am 47(5): 1060-1069.

31. Reynolds BM, Balsamon A (1983) Pelvis fracture.J trauma 13(11): 10111014.

32. Riou B, Laude F (2001) Trauma of the pelvis. In: Serious trauma. Arnette, Paris, France, 25: 437-447.

33. Schmal H, Markmiller M, Mehlhorn AT, Sudkamp NP (2005) Epidemiology and outcome of complex pelvic injury. Act orthop belg 71(1): 41-47.

34. Smith WR, Ziran BH, Morgan SJ (2007) Fractures of the pelvis and acetabulum.Informa healthcare, USA 1-26.

35. Strauss C and Palau (1996) Fractures of the pelvis.Medical-Surgical Encyclopaedia 31: 41-51.

36. Theumann N, Schnyder P (2007) Pelvic fracture. In Emergency radiology. Springer Berlin, Heidelberg 2(10): 225-249.

37. Tonetti J (2005) Unstable extra cotyloid fractures of the pelvic ringTeaching conferences, Elsevier, Paris, France, p. 1-9.

38. Traore Bakary (2005) Fractures of the pelvis in the orthopedic surgery and trauma department of Gabriel Touré Hospital. About 36 cases. Medical Thesis, Bamako $\mathrm{N}^{\circ} 88$.

39. Rothenberger D, Velasco R, Strate R, Fischer RP, Perry JF (1978) Open pelvic fracture lethal injury. J Trauma (USA) 18(3): 183-187. 


\section{(C) (i) This work is licensed under Creative}

Submission Link: https://biomedres.us/submit-manuscript.php

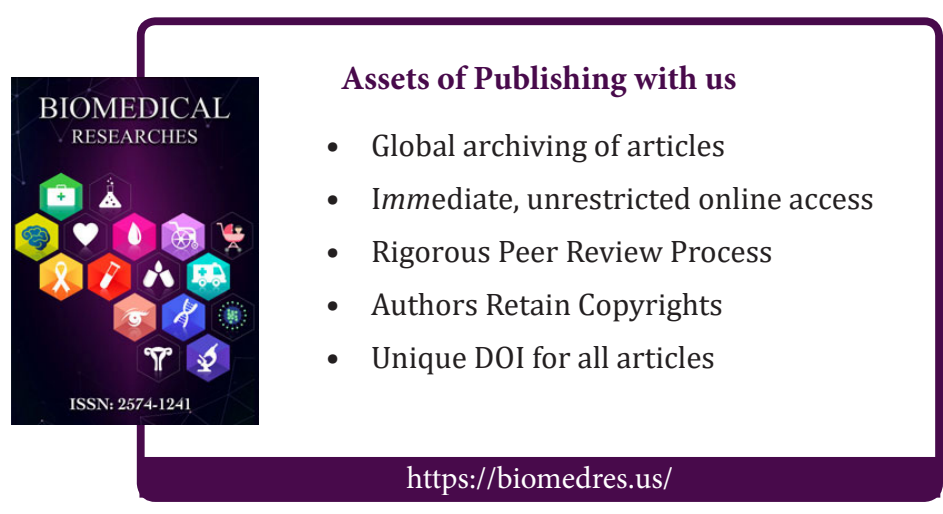

